\title{
ANALISIS DAN IMPLEMENTASI JARINGAN THIN CLIENT MENGGUNAKAN LINUX TERMINAL SERVER PROJECT PADA JARINGAN LAN
}

\author{
Doli Hasibuan ${ }^{1}$, Fati GN Larosa², Rico VA Simanjuntak ${ }^{3}$ \\ 1,2,3 Fakultas Ilmu Komputer, \\ Universitas Methodist Indonesia \\ hasibuan.doli@gmail.com
}

\begin{abstract}
The development of computer technology both in software and hardware is very fast. These two aspects are interrelated with each other and cannot be separated. LTSP, Linux Terminal Server Project is a project started by James A McQuillan as a diskless networking project based on the GNU/linux operating system. Called diskless network, because the client is not equipped with a hard disk. All application software and operating systems needed by the client computer are served and managed by the server computer. In this design, a laptop with an Intel processor is used as a server, and a PC as a client. LTSP will be integrated into the Linux operating system ubuntu 16.04, and as a provider of diskless thin client service platforms is LTSP (Linux Terminal Server Project). With LTSP, the construction of a diskless network is expected to be more efficient. Diskless network technology is one solution that can be applied in dealing with the problem of investing in computer technology hardware with predetermined specifications.
\end{abstract}

\section{Keywords: LTSP, Server, Thin Client, Ubuntu}

\section{PENDAHULUAN}

Diskless komputer merupakan penggunaan PC secara bersama sama oleh dua user/client atau lebih, hanya membutuhkan floppy drive atau bootrom untuk mengaktifkan LTSP (Linux Terminal Server Project) di user PC. Untuk membuat sistem tersebut server harus menjalankan beberapa service-service seperti DHCP (Dynamic host Configuration Protocol), dan paket LTSP. Pengupayaan pengembangan sistem diskless menggunakan LTSP (Linux Service Terminal Project) akan dimanfaatkan untuk keperluan kerja. Keuntungan penggunaan diskless komputer seperti backup data terpusat di server dan dibutuhkannya lebih sedikit administrasi diskless client. Membangun jaringan dengan menggunakan Linux Terminal Server Project (LTSP) Server dapat membantu aktifitas yang memiliki investasi terbatas dalam membangun satu jaringan komputer. Dalam penelitian ini, akan diuraikan beberapa permasalahan yang kemudian diusahakan solusinya.

\section{KAJIAN TEORI}

\section{Konsep Sistem Operasi}

Sistem operasi mempunyai peranan yang sangat penting dalam sistem berbasis komputer. Modern Operating system, ada dua tugas utama sistem operasi. kedua tugas tersebut yaitu sistem operasi sebagai extended machine dan sistem operasi sebagai resource manager. Sistem operasi sebagai extended machine artinya sistem operasi bertugas untuk menyembunyikan kerumitan hardware dan menyediakan antarmuka yang lebih mudah dipakai pengguna. Sedangkan sistem operasi sebagai resource manager berarti sistem operasi berfungsi sebagai pengatur sumber daya yang ada di komputer baik itu jaringan, software aplikasi, hardware atau sumber daya lainya.

\section{Linux}

GNU/Linux adalah sistem operasi yang dibuat oleh Linus Benedict Torvalds dan disebarkan secara bebas di internet dimana orang lain bisa mengembangkan dan menggunakan untuk keperluannya sendiri. Namun, perlu dijelaskan bahwa GNU/Linux disini bisa bermakna ganda. Pertama, GNU/Linux berarti kernel linux. Pengertian kedua berarti sebuah sistem yang didalamnya sudah terdapat kernel, shell dan program pendukung lain yang siap di distribusikan dan dipakai. GNU/Linux dalam penelitian ini mengacu pada pengertian yang kedua. GNU/Linux adalah sistem operasi yang bebas dipakai, didistribusikan dan dikembangkan kembali. Oleh karena itu, GNU/Linux mempunyai banyak varian yang lebih dikenal dengan istilah distro.

Filesystem

Filesystem adalah metode dan struktur data pada sebuah sistem operasi yang mengatur berkas pada sebuah disk atau partisi. GNU/Linux merupakan sistem operasi yang masih satu keluarga dengan UNIX dimana keduanya mempunyai struktur direktori yang sudah baku.

\section{Jaringan Thin Client}

Komputer server akan menyediakan berbagai sumber daya terdistribusi kepada pengguna pada jaringan thin client, meliputi Central Processing Unit ( $C P U)$, memori, sistem operasi dan aplikasi. Pengguna dapat mengoperasikan aplikasi melalui perangkat masukan 
dan keluaran sebagai media pengendali dan penampil dengan perantara protokol komunikasi client-server dan layanan terminal server sebagai pemberi akses penggunaan sumber daya server. Alokasi sistem operasi dan perangkat lunak kerja setiap pengguna dilakukan dengan konsep virtualisasi desktop dari sistem operasi server yang ditenggarai oleh terminal server.

\section{Teknologi Terminal Server}

Terminal server dalam bahasa sederhana sering disebut dengan teknologi kloning, sebuah PC Server yang besar diakses oleh banyak PC workstation melalui jaringan LAN agar merasakan kecepatan yang hampir sama dengan PC Server yang besar tersebut. Pada sisi ekstrem kita dapat menggunakan PC tanpa harddisk (diskless) sebagai workstation. Kita dapat menggunakan mesin 486 dengan RAM 16 Mbyte, PC jenis ini sangat cocok untuk digunakan sebagai client workstation, tanpa perlu dipasangi harddisk.

\section{Protokol Jaringan Komputer}

Protokol adalah sebuah aturan atau standar yang mengatur atau mengijinkan terjadinya hubungan, komunikasi, dan perpindahan data antara dua atau lebih titik komputer. Protokol dapat diterapkan pada perangkat keras, perangkat lunak atau kombinasi dari keduanya. Pada tingkatan yang terendah, protokol mendefinisikan koneksi perangkat keras

\section{Server}

Server adalah sebuah sistem komputer yang menyediakan jenis layanan tertentu dalam sebuah jaringan komputer. Server didukung dengan prosesor yang bersifat scalable dan RAM yang besar, juga dilengkapi dengan sistem operasi khusus, yang disebut sebagai sistem operasi jaringan atau network operating system. Server juga menjalankan perangkat lunak administratif yang mengontrol akses terhadap jaringan dan sumber daya yang terdapat di dalamnya, seperti halnya berkas atau alat pencetak (printer), dan memberikan akses kepada workstation anggota jaringan.

\section{ANALISIS DAN PERANCANGAN SISTEM}

Seringkali pengadaan infrastruktur komputer terbentur pada masalah optimalisasi penggunaan perangkatnya yang harus menyesuaikan perkembangan teknologi yang diadopsi seperti sistem operasi atau perangkat lunak yang digunakan. Hal ini disebabkan penggunaan arsitektur yang umumnya mengharuskan kompabilitas semua perangkat yang digunakan. Solusi dari masalah tersebut adalah dengan menerapkan arsitektur thin-client, sehingga tidak semua perangkat komputer harus di upgrade atau diganti. Hanya perangkat di sisi server saja yang disesuaikan agar dapar mengadopsi teknologi sistem operasi dan perangkat lunaknya, dalam artian memenuhi kompabilitas yang diinginkan.

\section{Deskripsi Sistem}

LTSP adalah kepanjangan dari Linux terminal Server Project yang dikembangkan oleh James McQuillan (www.ltsp.org). LTSP adalah paket add-on dari linux yang memungkinkan banyak user bekerja pada sebuah komputer. Seluruh aplikasi berjalan pada server dan terminal hanya menangani input dan output.

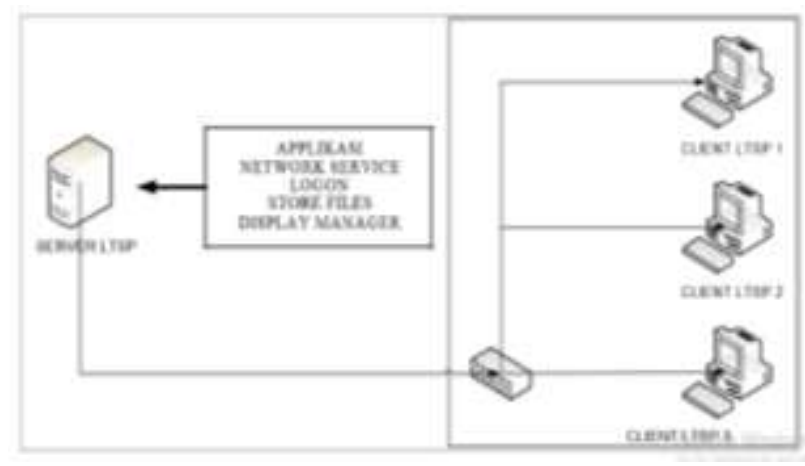

Gambar 1. Terminal menangani input dan output

\section{Analisis Sistem Linux Terminal Server Project}

Cara kerja LTSP adalah pada saat komputer klien melakukan booting dari Preboot Execution Environment (PXE) klien me-request alamat IP dari server LTSP melalui protokol DHCP (server). Kemudian memuat Linux kernel dari preconfigured Linux Image menggunakan protokol TFTP (Trivial File Transfer Protokol) yang telah berjalan pada servis server LTSP. Kemudian server menentukan path untuk lingkungan chroot setiap client. Hal ini dilakukan oleh protokol NFS (Network File System). Lalu klien melakukan mounts (pengenalan dan penerapann) path dari root-nya itu. Setelah itu klien memanggil paket-paket Linux dan pada akhirnya memulai memanggil interface grafik (X Windowing System) sehingga terkoneksi ke login manager (XDMCP) dari server LTSP

\section{Analisis Jaringan Komputer}

Tipe ini digunakan karena jaringan dibangun di satu ruangan dengan jangkauan kecil. LAN merupakan salah satu arsitektur jaringan yang paling sederhana dan dapat dikembangkan menjadi arsitektur jaringan yang cukup luas cakupannya. Luas cakupan LAN itu sendiri tidak melebihi dari satu area yang terdiri dari beberapa terminal yang saling dihubungkan, sehingga menambahkan fungsi dari terminal itu sendiri.

Jaringan komputer yang digunakan dalam sistem Linux Terminal Server Project (LTSP) ini adalah sebagai berikut :

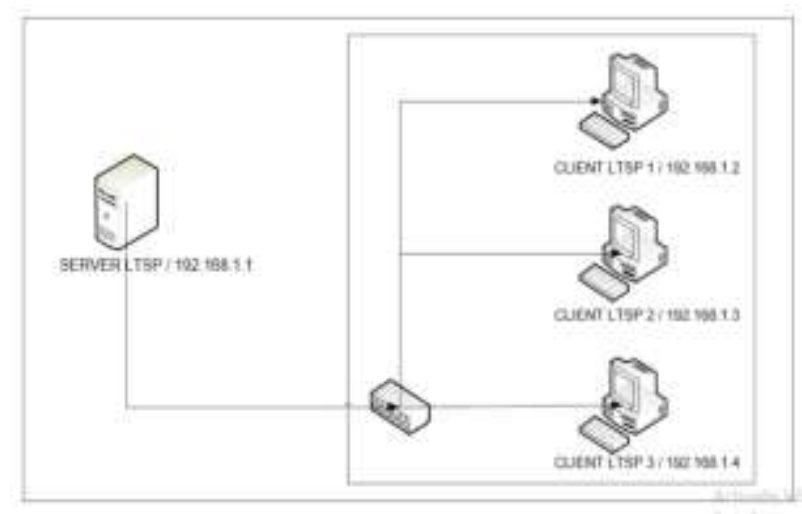

Gambar 2. Terminal Server Project 


\section{Perancangan paket kernel versi 3.0 untuk server LTSP}

Persiapan sebelum melakukan pembangunan dan instalasi paket kernel dengan metode manual, dilakukan dalam mode user root, yaitu login sebagai root dan mempersiapkan mesin untuk mengkompilasi kernel versi 3.0 semua dilakukan di Terminal. Paket-paket yang dibutuhkan diantaranya :

1. Paket kernel-package, digunakan sebagai paket kernel yang akan menjadi pedoman saat akan melakukan pengkonfigurasian kernel source, sebelum kernel source akan di kompilasi sesuai dengan kebutuhan dan menyediakan kemampuan untuk membuat paket kernel-image debian.

2. Paket gcc (GNU Compiler Collection), yakni program untuk mengkompilasi source code $\mathrm{C}$. Kernel Linux sendiri ditulis untuk dapat dikompilasi oleh GCC, sehingga paket ini dibutuhkan untuk mengkompilasi paket kernel.

3. Paket libncurses5-dev, digunakan agar saat melakukan kompilsai pada kernel source dapat menampilkan modus grafik (GUI) dari kernel source yang akan dikompilasi sehingga memudahkan dalam melakukan kompilasi kernel linux.

4. Paket fakeroot, berfungsi untuk menyamarkan user yang akan digunakan, seolah olah menjadi user root.

5. Paket wget dan bzip2, aplikasi download manager yang ada pada sistem operasi linux, biasanya aplikasi ini telah menjadi paket default dari linux. Sedangkan paket bzip2 digunakan untuk mengekstrak atau menguraikan file terkompresi berbentuk tar.gz2 dan sama seperti wget, paket ini sudah terinstal secara default.

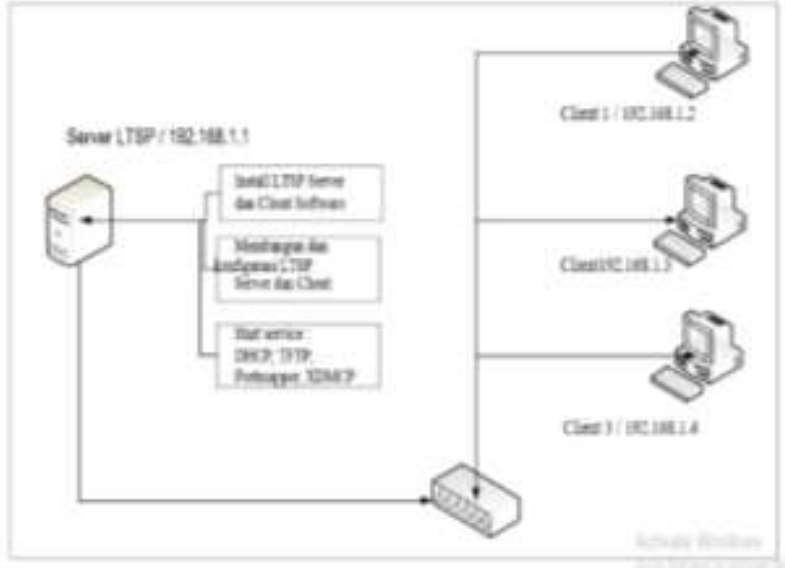

Gambar 3. Persiapan untuk mengkompilasi kernel

Flowchart atau diagram alir dari proses Linux Terminal Server Project (LTSP) adalah sebagai berikut :

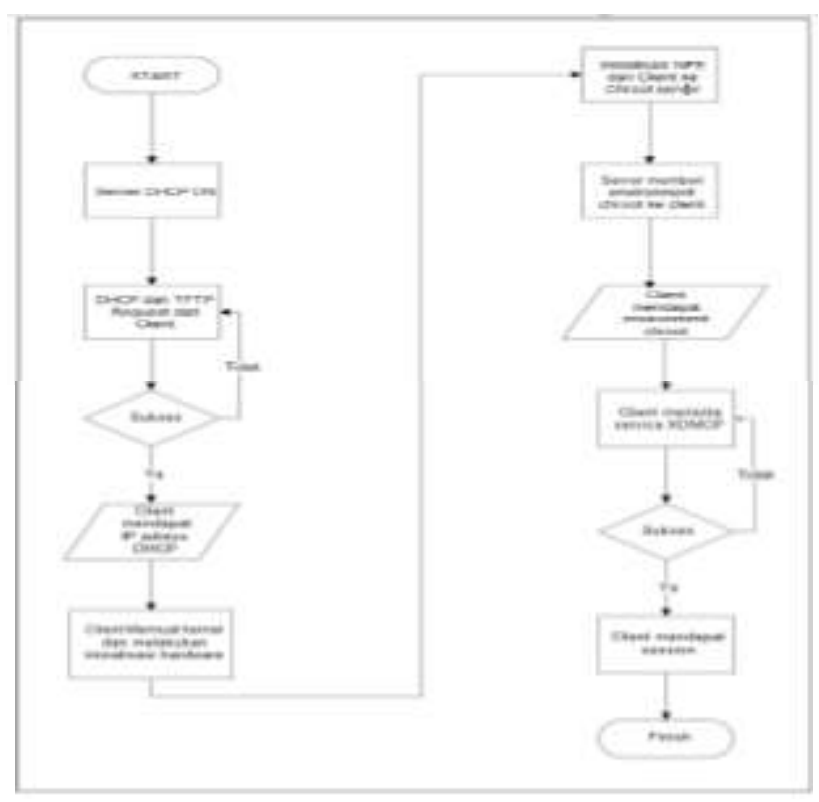

Gambar 4. Diagram Alir dari proses Linux Terminal

\section{IMPLEMENTASI DAN PENGUJIAN SISTEM}

\section{Instalisasi Server Linux Terminal Server Project ( LTSP ) pada Ubuntu 16.04}

Langkah pertama anda harus install dan konfigurasi openssh dengan perintah sudo apt-get install opensshserver, seperti pada gambar

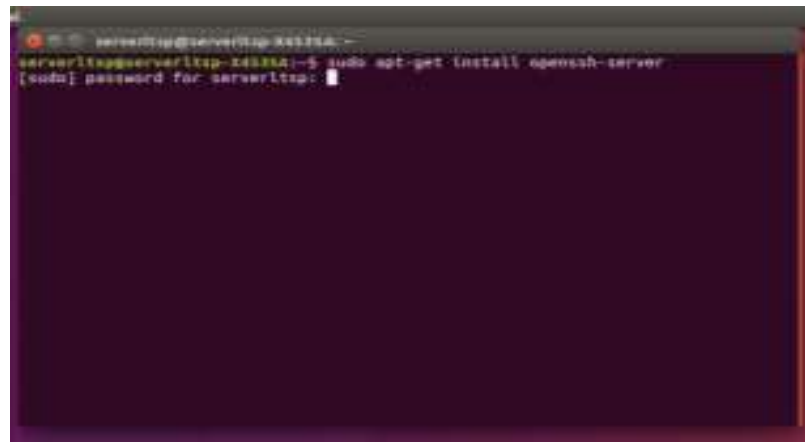

Gambar 5. Instalasi dan Konfigurasi openssh

Kemudian Install ltsp-server-standalone pada server, dengan perintah sudo apt-get install Itsp-serverstandalone, seperti pada gambar 


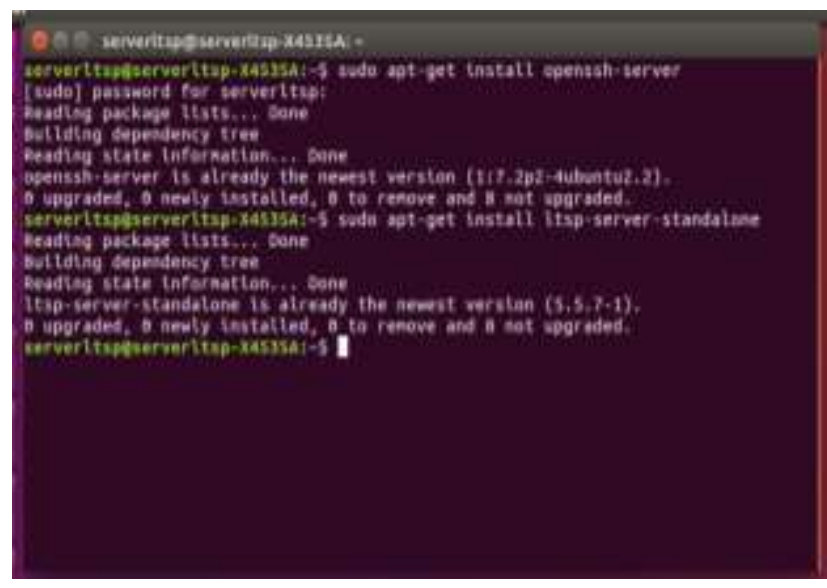

Gambar 6. Instalasi ltsp-server-standalone pada server, dengan perintah sudo apt-get install

Sealnjutnya dilakukan konfigurasi dhcp di letc/ltsp/dhcpd.conf. dengan perintah sudo nano /etc/ltsp/dhcp.conf, seperti pada gambar 7 .

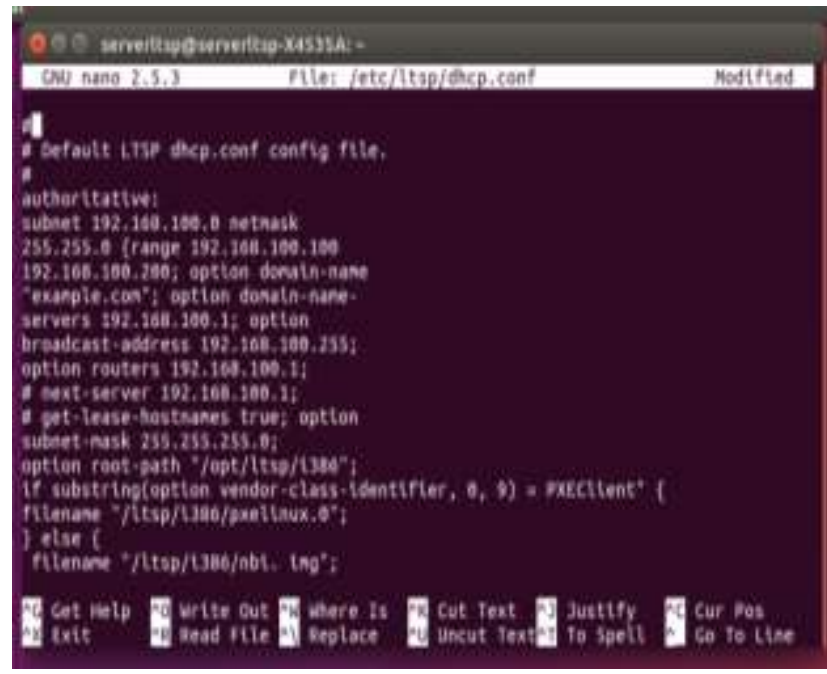

Gambar 7. Konfigurasi dhcp

Langkah selanjutnya membuat user client LTSP, dengan perintah sudo adduser universitasmethodist. Disini boleh saja membuat nama user dengan nama lain sesuai keinginan pengguna, seperti pada gambar 8 .

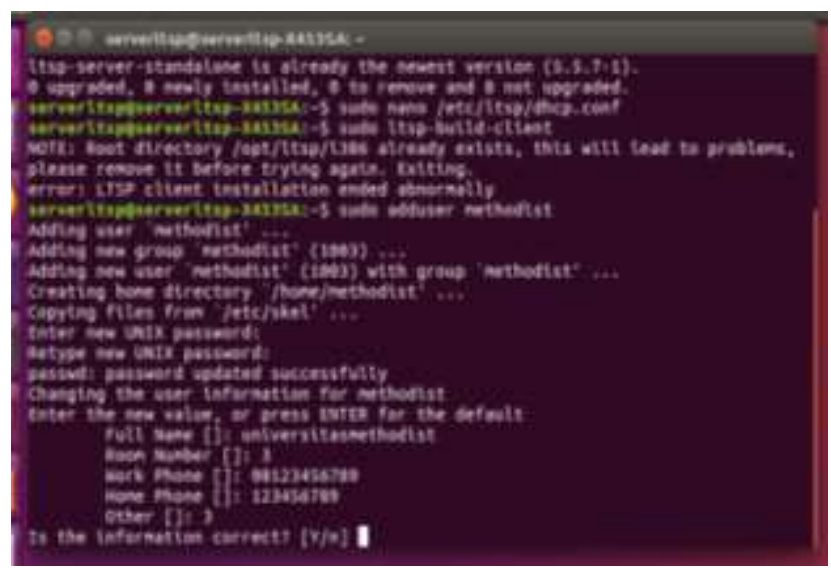

Gambar 8. Pembuatan user client LTSP, dengan
Kemudian lakukan update-kernels, dengan perintah sudo Itsp-update-kernels

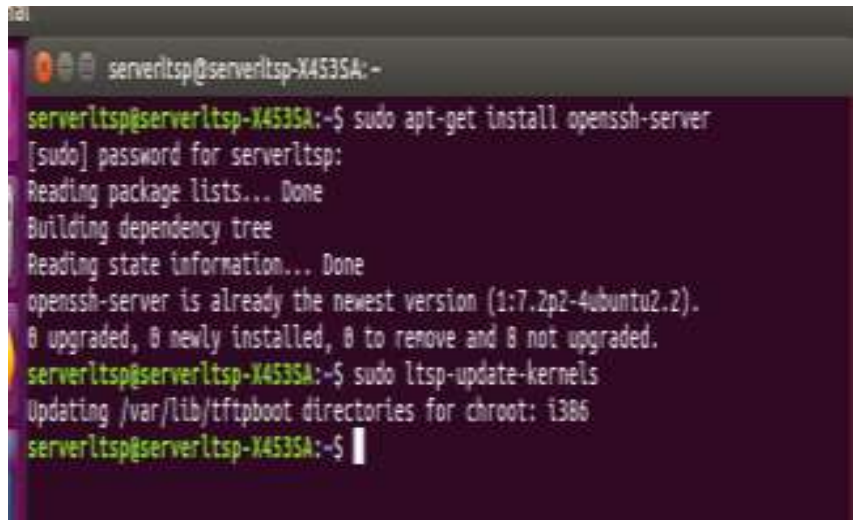

Gambar 9. Pembuatan update-kernels

Selanjutnya lakukan update-image, dengan mengetikkan perintah sudo ltsp-update-image, seperti pada gambar

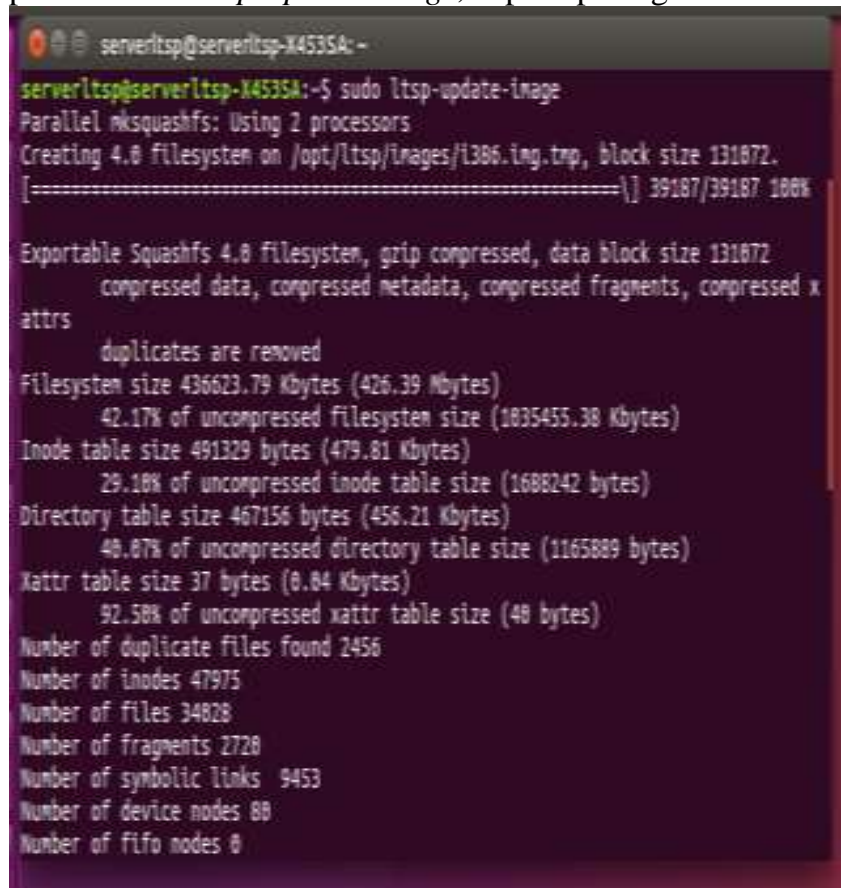

Gambar 10. update-image

\section{Pengujian Open Office}

Pada client membuat sebuah project dokumen, seperti pada gambar

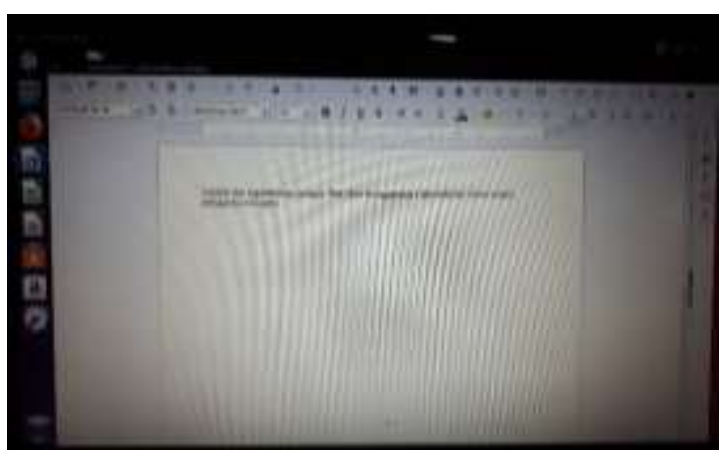

Gambar 11. Membuat sebuah project dokumen 


\section{Sharing Internet}

Disini server terlebih dahulu koneksi ke internet dengan nama wifi A5 (2017), seperti pada gambar 12.

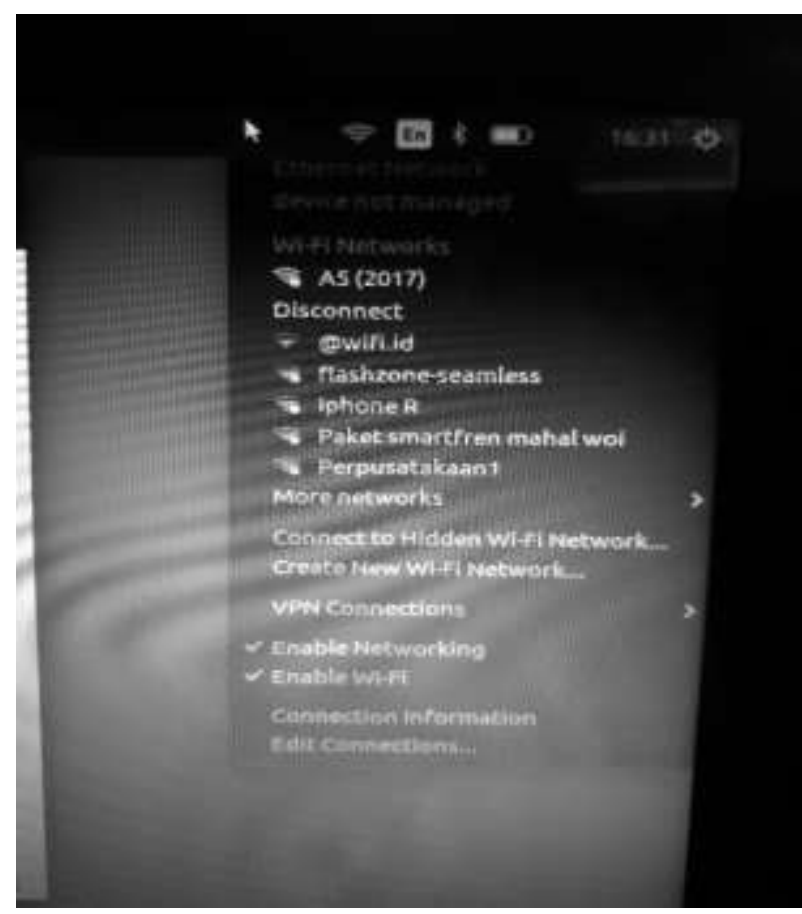

Gambar 12. Koneksi ke internet dengan nama wifi A5 (2017)

\section{KESIMPULAN}

Berdasarkan pengujian yang telah dilakukan dan analisis hasil pengujian, diperoleh kesimpulan sebagai berikut :

1. Implementasi jaringan diskless thin client LTSP pada pengujian kali ini dapat berjalan dengan baik, dan dapat digunakan untuk melakukan pengujian dengan menggunakan jaringan LAN

2. Besarnya beban paket jaringan pada jaringan thin client LTSP dipengaruhi oleh banyaknya aktifitas yang terjadi antar server dengan client. Aktifitas yang dimaksud ini merupakan kegiatan menjalankan aplikasi di client

3. Hasil dari penelitian ini dapat digunakan untuk menyimpan data client pada server tanpa harus memikirkan penyimpanan Hardisk pada client

Setelah melakukan penelitian ini dapat perlu dilakukan penelitian lanjutan berhubugan dengan beban trafik jaringan dengan jumlah client yang terkoneksi.

\section{DAFTAR PUSTAKA}

[1]. Andri Kristianto, "Jaringan Komputer",Graha Ilmu, Jakarta 2003.

[2]. http://;tsp.org/documentation/ltsp-4.1/ltsp-4.1.3-en.html

[3]. http://www.linux.or.id

[4]. http://www.ltsp.org

[5]. http://arievaldano.wordpress.com/2011/10/02/mengenalteknologi-thin-client network/

[6]. http://www.bosimanurung.com.com

[7]. James McQuillan, "LTSP - Linux Terminal Server Project $-\mathrm{v} 4.1 "$
[8]. Linux Terminal Server Project, URL : http://www.ltsp.org, (Oktober 2009)

[9]. LTSP How To,URL: http//www.ubuntu.com, (Oktober 2009)

[10].Purbo, Onno W. 2006 .PC Cloning Windows pakai Linux LTSP. Penerbit Andi.Yogyakarta.

[11].Utdirartatmo, Firrar. 2004 .Clustering PC di Linux dengan OpenMosix dan ClusterKnoppix. Penerbit Andi. Yogyakarta.

[12].Wahan Komputer Profesional, “Konsep Jaringan Komputer dan Pengembangan", Salemba Infotek, Jakarta 2003. 